\title{
The Economic Impact, Contribution, and Challenges of Micro Business Enterprises to the Local Development
}

\author{
Joyfe G. Quingco \\ Carlos Hilado Memorial State College-Fortune Towne Campus, Philippines \\ joyfegquingco41@gmail.com \\ https://orcid.org/0000-0002-6472-6463 \\ Carmenda S. Leonoras \\ University of Negros Occidental-Recoletos, Bacolod City, Philippines \\ csleonoras@gmail.com
}

\begin{abstract}
Micro Business Enterprises (MBEs) is the lifeblood for economic development. Using a descriptive quantitative research design, the study aimed to investigate the impact of MBEs to economic development. As to impact, in general, it was of a moderate extent. Among the indicators, technology has the highest mean interpreted to a high extent, while infrastructure development scored the lowest mean score, which reflected a moderate degree. The study further delved into the economic contribution and challenges encountered by MBEs. The findings basically implied that MBEs were rooted in the entrepreneur's commitment to do business that promotes progress and development to the local economy.
\end{abstract}

Keywords: Micro business, Economic Impact, Contribution, and Challenges, Descriptive Research Design, Local Development, Bacolod City, Philippines

Date Submitted: October 29, 2019

Date Revised: December 13, 2019

Date Accepted: December 29, 2019

\subsection{Introduction}

The pursuit of economic development is the objective of many growing countries Worldwide (Opafunso \& Adepoju, 2014). Developing countries confront several problems, such as the high rate of poverty and unemployment, which continue to impede the attainment of economic development (Opafunso et al., 2014). MBE is a small business that is usually operated by not more than ten people and usually starts with a small amount of capital. MBEs abound in the economy, and they are seen everywhere (Simbre, 2017). They are considered the engine of economic growth that 
promotes equitable development (Nishanth, 2014). Also, MBE's refer to entities that employ few workers and which are usually run by the owners who report low to average revenue and assets; these owners do not hold stakes in subsidiaries, associate entities, or joint ventures (Mackowiak, 2017).

According to Nishanth (2014), MBEs play a vital role in developing the economic condition of a country to lessen poverty and attain sustainable growth. One of the advantages of MBEs is seen in its nature of business as it leads to an equitable distribution of income. Moreover, MBEs help the inefficient allocation of resources in a country by implementing labor-intensive production processes, given the abundant supply of labor force in countries wherein capital is scarce Nishanth (2014).

In this study, the contribution of MBEs to local economic development identified are income generation, local competitiveness, and poverty alleviation (Yahaya, Geidam, \& Usman, 2016).

Despite its relevance, these micro enterprises encounter some problems like the absence of sufficient and available supply of financing, difficulties in buying raw materials, marketing and distribution challenges, and the non-availability of suitable technology. The existing problem on access to funding may be different in each region, sector, or individual enterprise in an industry (Nishanth, 2014).

Navarathne (2017) identified operational and managerial challenges, such as maintaining a superior quality of products and services, innovating the technology, business rules and regulations-related issues, competition, and infrastructure issues. In ASEAN countries, MBEs are found to be the critical factors in the economy, accounting for the rising shares in employment. Studies on MBEs in the ASEAN countries exhibit that MBEs enhance the development of production networks for higher intensity and higher-end processes and products, based on vertical specialization and arm's length transactions, stimulating local entrepreneurship, competitiveness, and businesses (Bobowski, 2017).

In the Philippines, micro-enterprise considered the lifeblood of the economy. MBEs create avenues for ethical trade and promote productivity by providing incomegenerating activities for a significant portion of the population, which are considered vital in developing the countryside and stimulating local tourism (Abellanosa, 2014).

Micro Business Enterprises (MBEs) are significant to the economy of the country. In 2014, the Philippine Statistics Authority (PSA) estimated micro enterprises to have reached around $90.3 \%$ among the business establishments in the Philippines (Almerino, 2016).

Republic Act 9178 or the Barangay (Community) Micro Business Enterprise (BMBE) Act is one of the programs of the Philippine government which strengthens the BMBEs through the incentives and other benefits such as exemption from income tax, exemption from minimum wage, reduction of local government taxes, fees and charges, particular credit window for financing, technology transfer and other business development assistance. Qualified MBEs can register with asset size of up to three million pesos $(\mathrm{P} 3,000,000.00)$ in production, processing, or manufacturing of products, including agro-processing (Simbre, 2017).

Despite the Republic Act 9178, many MBEs are not registered entities. MBEs may benefit from not issuing receipts and paying taxes, but not registering deprives 
them of the opportunity to grow, which the licensed MBEs enjoy. So far, no formal local studies have been made to determine the economic impact, the contributions, and the everyday challenges of this Micro Business Enterprise to the local economy. However, previous studies delved into factors affecting the operational efficiency of MBEs, the role of micro-businesses in the socio-economic and effectiveness of the implementation of MBE law (Abellanosa, 2014).

Hence, this paper aimed to determine the economic impact of Micro Business Enterprises (MBEs) to the local economy in Bacolod City in terms of infrastructure development, job creation, tax collection, and technology. Also, it investigated the economic contribution of MBEs in terms of income generation, local competitiveness, and poverty alleviation. Likewise, it explored the current challenges faced by MBEs.

\subsection{Framework of the Study}

The framework of the study focused on the economic contributions, the economic impact of Micro Business Enterprises to the local economy, society, and individuals as well as the common operational challenges. The economic contributions like income generation, local competitiveness, and poverty alleviation bear significance to the local economic development (Chowdhury, 2016). The more MBEs contribute, the higher the importance.

Moreover, as the contribution becomes active, it yields a high impact on the local economy like infrastructure development, job creation, technology, and tax collection (Magar, 2017).

Prevailing challenges experienced in the operation of the business-like access to financial services, cost of technology, employee turnover, existence of competitors, lack of barangay micro business enterprise campaign, lack of managerial skills, limited access to market, low demand of product and services, small profits are determinants in the success of the Micro Business Enterprise (Maloka, 2013).

The output of the study would help the micro-business owners to plan and organize a business venture by established criteria and procedures supported by an action plan and implementing a business policy.

\subsection{Methods}

The present study used a descriptive research design applying the survey questionnaire method. Respondents of the survey were the selected progressive barangays with registered Barangay Micro Business Enterprises (BMBEs) of Bacolod City. Sixty MBEs owners acted as respondents that belonged to 24 barangays operating as trade and merchandising businesses using purposive sampling and who were currently doing for the last five years. A list of BMBEs was acquired from the City Treasurer's Office Licensing Division.

Using the survey method, a researcher-made questionnaire was validated using Good and Scates standard with a score of 3.5. It was pilot tested with 30 micro business owners who are registered in the BMBE of Talisay City to obtain reliability using the Cronbach Alpha Method. The test score was 0.976.

Data obtained from the instruments were subjected to descriptive analysis and appropriate statistical tools to interpret the data. Using the mean and standard 
deviation, problems that sought to determine the extent of the economic impact and contributions of Micro Business Enterprises to the local economy. On the other hand, for the problem which sought to determine the current challenges faced by the Micro Business Enterprises, frequency and percentage distribution were used.

\subsection{Results and Discussion}

\section{Extent of Economic Impact of Micro Business Enterprises}

Infrastructure Development. Table 1 shows that the extent of the economic impact of $\mathrm{MBE}$ to infrastructure development as a whole is moderate $(M=3.11 ; S D=0.77)$. "Upgrades the operation process" got the highest score of 3.23, which was interpreted as high extent while "increases in capital invested" got the lowest score of 2.92, which was also interpreted as a moderate extent.

As the business upgrades operational processes, infrastructural development flourishes as proven by acquiring additional facilities to enhance operational efficiency and productivity. Operating profit surplus was reinvested; thus, the micro-business owners are not required to make cash outlay as an additional investment. Respondents rated increases capital invested low because they consider that earnings are rolled back to the operations and not on the capital expenditures. Simply stated, the priority of these entrepreneurs is business survival rather than investing in equipment.

The improvement in facilities and the production of goods and services contribute to the betterment of the operations of the business. According to Magar (2017), the lack of proper infrastructural facilities causes severe damage to the enterprise's value chain process, which includes production, consumption, and distribution of the products. This impediment is apart from the absence of finances, inadequate marketing facilities, and technological obsolescence that are already being faced by MSMEs.

Moreover, infrastructure development supports business development as confirmed by World Economic Forum (2014), well-developed infrastructure not only reduces the distance between regions but also integrates national markets and connects them at low costs to other economies (Ismail, 2015).

On the other hand, infrastructural development increases the capital invested. Requirements are necessary for current infrastructure projects for Micro, Small, and

Table 1. Extent of Economic Impact of MBE in terms of Infrastructure Development

\begin{tabular}{llll} 
Infrastructure Development & Mean & SD & Int \\
\hline 1. Generates improvement in facilities. & 3.15 & 0.67 & $\mathrm{ME}$ \\
2. Upgrades the operation process. & 3.23 & 0.71 & $\mathrm{HE}$ \\
3. Increases in the production of goods and services. & 3.15 & 0.78 & $\mathrm{ME}$ \\
4. Increases in capital invested. & 2.92 & 0.84 & $\mathrm{ME}$ \\
5. Promotes new business opportunities. & 3.08 & 0.84 & $\mathrm{ME}$ \\
Average & 3.11 & 0.77 & $\mathrm{ME}$ \\
\hline Note: ME=Moderate Extent, $\mathrm{HE}=$ High Extent & & &
\end{tabular}


Medium Enterprises (MSMEs). With this, all MSMEs come together and share the costs of infrastructure, which are a costly affair for individual MSMEs (Magar, 2017).

Job Creation. Table 2 shows that the economic impact of MBEs to job creation as a whole is a high extent $(M=3.62 ; S D=0.82)$. It implies that $M B E s$ help create jobs and decrease the unemployment problem in the community.

Micro Business Enterprises "promote self-sufficiency of employees" was rated a high extent $(M=3.85)$, which means $M B E$ operations provide employment and increases individual or family income. On the other hand, "increase employed residents in the area" was rated a moderate extent $(M=3.31)$. MBEs owners often hire employees who are not from the community they operate. Therefore, it is not absolute that MBE's employ only residence coming from the city.

Table 2. Extent of Economic Impact of MBE in terms of Job Creation

\begin{tabular}{llll}
\hline Job Creation & Mean & SD & Int \\
\hline 1. Provides employment in the local society. & 3.46 & 0.64 & $\mathrm{ME}$ \\
2. Improves individual/family income. & 3.69 & 0.73 & $\mathrm{HE}$ \\
3. Increase employed residents in the area. & 3.31 & 1.08 & $\mathrm{ME}$ \\
4. Promotes the self-sufficiency of employees. & 3.85 & 0.54 & $\mathrm{HE}$ \\
5. Provides training skills to the employees. & 3.77 & 0.90 & $\mathrm{HE}$ \\
Average & 3.62 & 0.82 & $\mathrm{HE}$ \\
\hline
\end{tabular}

Note: ME=Moderate Extent, $\mathrm{HE}=$ High Extent

According to Ajuwon, Ikhide, and Akotey (2015), job creation has come to recognize the significant role that MBEs play in any economy's development. Business owners believe that as it offers employment of the residents of the local community, it promotes self-sufficiency, provides skills training, and improves an individual's family income. As the number of business enterprises operates, it gives employment opportunities and increases the per capita income of the residents.

MBEs often hired non-local residents due to the scarcity of local employees, for they chose to seek and gain employment bigger companies that offer better salary packages.

Micro-businesses play a significant role in economic development by providing both employment, goods, and services. As a result, MBEs improve individual/family income, according to Baptiste-Cornelis (2015).

Tax Collection. Table 3 shows that the economic impact of MBEs to tax collection as a whole is a high extent $(M=3.54 ; S D=0.83)$. It considered that top tax collection gives the local community the best opportunity to receive essential services. As a result, improvement or development on the local community is visible as business enterprises bloom or prosper.

The results of the survey show that "tax collections from new businesses" got the highest mean score of 3.77 and a standard deviation of 0.81 , which was interpreted 
as a high extent. An increase in sales tax, business permits, and licenses are brought about by new micro-businesses and also other types of business. On the other hand, "assures infrastructure development from taxes" got the lowest mean score of 3.31 and a standard deviation of 0.61 , which was interpreted as a moderate extent. Thus, not all infrastructure developments in the community came from the local budget but also income-generating national budget and appropriation.

Increased sales tax collection came from increased sales. Sales tax revenue is given to the local economy because these are used to meet community needs (De Renzy, 2014). This confirms that the collection of business taxes, like fees on permits and licenses, is contributory to the economic impact of MBEs to the local economy. The increase in sales revenue and tax collection is part and parcel of total collections generated by the government. Economists discussed that the resources of companies directed as to tax compliance are resources that could be used for reinvestment, and facilitating future growth. Hence, there is a belief that the tax and complicated tax system has pressured the business and does not warrant infrastructural development in the area Adebisi (2013).

Table 3. Extent of Economic Impact of MBE in terms of Tax Collection

\begin{tabular}{llll}
\hline Tax Collection & Mean & SD & Int \\
\hline $\begin{array}{l}\text { 1. Collects business taxes from the new branch. } \\
\text { 2. Promotes higher individual income taxes. }\end{array}$ & 3.77 & 0.81 & $\mathrm{HE}$ \\
$\begin{array}{l}\text { 3. Provides funds to local government for the delivery } \\
\text { of basic services. }\end{array}$ & 3.46 & 0.85 & $\mathrm{HE}$ \\
$\begin{array}{l}\text { 4. Assures infrastructure development from taxes. } \\
\begin{array}{l}\text { 5. Supports the Barangay Micro Business Enterprise } \\
\text { law implementation. }\end{array}\end{array}$ & 3.31 & 0.61 & $\mathrm{ME}$ \\
\begin{tabular}{l} 
Average \\
\hline
\end{tabular} & 3.54 & 1.10 & $\mathrm{HE}$ \\
\hline
\end{tabular}

Note: $\mathrm{ME}=$ Moderate Extent, $\mathrm{HE}=$ High Extent

Technology. Table 4 shows that the extent of micro-enterprises' economic impact of MBEs to technology is high ( $S=3.63 ; S D=0.78)$. Advancement in technology like internet e-commerce and other gadgets helps to do business fast and easy.

Technology improves the connection to suppliers or their marketability as manifested by a mean score of 4.08 and a standard deviation of 0.74 , which was interpreted as a high extent. The presence of high technology provides convenience to MBEs. The low mean score was on the "improves business process efficiently and improves employee's' productivity" (M=3.38), which was interpreted as a moderate extent. It implies that the use of high technology decreases human productivity as employees rely on the use of technology. The decrease in human productivity is brought about by the oppressive or extensive use of modern technology in the business - the use of human labor decreases due to the replacement of technology that the human process can do. However, dealing perhaps with slow or obsolete technology and poor internet bandwidth can slow down even the most productive employees, and may warrant the need to upgrade existing hardware and software regularly proactively. 
According to Aruna (2015), nowadays, adopting the latest technology can improve the productivity of MBEs and overcome problems as well. Advancement in technology enhances business processes and promotes efficient customer service and employees' productivity. True to other advanced countries, wherein automation is generally applied in all business processes for all types of businesses.

Moreover, technology has revolutionized, and enterprises use a chain of technology, from servers to mobile devices, to develop competitive strengths in the economic marketplace. Business owners ought to think about implementing technology in their planning process for smooth integration and to provide room for future growth (Vitez, 2018).

Table 4. Extent of Economic Impact of MBE in terms of Technology

\begin{tabular}{llll}
\hline Technology & Mean & SD & Int \\
\hline 1. Improves business processes efficiently. & 3.38 & 0.75 & $\mathrm{ME}$ \\
2. Improves employee's productivity. & 3.38 & 0.75 & $\mathrm{ME}$ \\
3. Improves market activities. & 3.54 & 0.64 & $\mathrm{HE}$ \\
4. Provide efficient service to the customers. & 3.77 & 0.81 & $\mathrm{HE}$ \\
5. Improves connection to suppliers/marketability. & 4.08 & 0.74 & $\mathrm{HE}$ \\
Average & 3.63 & 0.78 & $\mathrm{HE}$ \\
\hline Note: ME=Moderate Extent, HE=High Extent & & &
\end{tabular}

Extent of Economic Impact of MBEs. Table 5 shows that when taken as a whole, the economic impact of Micro Business Enterprises (MBEs) to the local economy is a moderate extent $(M=3.47 ; S D=0.83)$.

It implies that the presence of MBEs in the community gives support to the local development of the economy, particularly on technology, which got a high mean score of 3.63 and interpreted as high extent while infrastructure development got a low mean micro-enterprise of 3.11 interpreted as moderate extent. There is visible infrastructure development in the local community but not as much as job creation, tax collection, and technology. Priorities of micro business owners (MBO) focused on improving the delivery of services and business innovation, which significantly affects income-generating activities.

Technology has changed the means that firms do business by enabling businesses to level the playing field with organizations. Businesses use a series of technology - everything from servers to mobile devices - to develop competitive advantages in the economic marketplace. Managers ought to think about implementing technology in their planning process for smooth integration and to provide room for future growth (Vitez, 2018).

Furthermore, the study, which anchored on the modern theory by Berry and Mazumdar (1991), was proven to be correct, which stated that development brings a natural birthplace for development and growth and enterprise of all sizes of establishments. 
Empirical studies related to economic management included analysis of financial problems and liquidity constraints. These studies contributed to the subject of micro-enterprises, filling some of the gaps in economic and financial management. Micro enterprises determine their impact on business performance under practices that focus on achieving the optimal level of liquidity and profitability that positively affect the performance of micro enterprises (Ramirez-Urquidy et al., 2018).

Table 5. Extent of Economic Impact of Micro Business Enterprises

\begin{tabular}{llll}
\hline \multicolumn{1}{c}{ To } & Mean & SD & Int \\
\hline Infrastructure Development & 3.11 & 0.77 & $\mathrm{ME}$ \\
Job Creation & 3.62 & 0.82 & $\mathrm{HE}$ \\
Tax Collection & 3.54 & 0.83 & $\mathrm{HE}$ \\
Technology & 3.63 & 0.78 & $\mathrm{HE}$ \\
As a Whole & 3.47 & 0.83 & $\mathrm{ME}$ \\
\hline
\end{tabular}

Note: $\mathrm{ME}=$ Moderate Extent, $\mathrm{HE}=$ High Extent

\section{Extent of Economic Contribution of MBEs}

Income Generation. Table 6 shows that the extent of the economic contribution of MBEs to income generation as a whole is high $(M=3.52 ; S D=0.81)$. It implies that Micro Business Enterprises provides opportunities to both local government and community to earn revenues through business permits and licenses and employment. Additional taxes are regularly collected, and residents are employed.

Result of the survey shows that indicator like high tax collection through business taxes got a mean score of 3.69 and was interpreted as a high extent. Micro businesses contribute to a more significant tax collection through sales tax payments and fees paid for business permits and licenses. Respondents moderately rated improvement of the standard of living as a contribution of micro-businesses, which got a low mean score of 3.38. Respondents believe that business engagements do not necessarily improve the standard of living because there are also other expenses or needs like food, education, clothing, and shelter that their income supports.

According to Hassan (2016), micro-enterprises play an essential role in income generation. These small-scale enterprises are more efficient in the nation's economy as they provide income generation opportunities for low-income groups.

In the study of Debela (2014), the informal sector's activities and small-scale manufacturing industries are eight times bigger than those engaged in the medium and large-scale industrial business comprising the ever-increasing significance of the MBE sector in the country's economy.

The result proved the findings in the study about Micro Business Enterprise development, which encompasses income-generating strategies and services ranging from education, skill training, and financial capital to low-income and small entrepreneurs (Jha, 2017). 
Table 6. Extent of the Economic Contribution of MBE in terms of Income Generation

\begin{tabular}{lccc}
\hline $\begin{array}{l}\text { Income Generation } \\
\text { 1. Provides income opportunity to local }\end{array}$ & Mean & SD & Int \\
residents. & 3.54 & 0.85 & $\mathrm{HE}$ \\
$\begin{array}{l}\text { 2. Improves the standard of living. } \\
\begin{array}{l}\text { 3. Results higher tax collection through } \\
\text { business tax (permits \& licenses) }\end{array}\end{array}$ & 3.38 & 0.85 & $\mathrm{ME}$ \\
$\begin{array}{l}\text { 4. Creates new products/services to the } \\
\text { market. }\end{array}$ & 3.69 & 0.73 & $\mathrm{HE}$ \\
$\begin{array}{l}\text { 5. Improves the quality of life of local } \\
\text { residents. }\end{array}$ & 3.54 & 0.76 & $\mathrm{ME}$ \\
\begin{tabular}{l} 
Average \\
\hline
\end{tabular} & 3.52 & 0.81 & $\mathrm{HE}$ \\
\hline
\end{tabular}

Note: $\mathrm{ME}=$ Moderate Extent, $\mathrm{HE}=$ High Extent

Local Competitiveness. Table 7 shows that the extent of the economic contribution of MBEs to the local competitiveness as a whole is high ( $M=3.68 ; S D=0.85)$. It implies that local competitiveness is the primary contributor to economic development. The entrepreneurs are operating under close competition to the advantage of consumers. Competition dictates that the suggested retail price becomes lower when there are many players. "Promotes a reasonable retail price" got a high mean score of 3.92 and was interpreted as high extent. Meanwhile, "promotes sustainable business and attracts new investment from other entrepreneurs" got low mean scores of 3.54 but interpreted as high extent. As the scenario for business engagements become better, many individuals become more interested in venturing into business.

In the study of Popescu, Corbos, and Bunea (2018), local competitiveness can improve the business environment of a city which includes the physical, social, and cultural infrastructure that can attract and retain profitable, innovative, and creative workforce to achieve high productivity, employment, high wage, gross domestic product per capita, but reduce income disparities and diminish social exclusion.

Table 7. Extent of the Economic Contribution of MBE in terms of Local Competitiveness

\begin{tabular}{|c|c|c|c|}
\hline Local Competitiveness & Mean & SD & Int \\
\hline $\begin{array}{l}\text { 1. Creates more opportunity for an } \\
\text { entrepreneur to grow. }\end{array}$ & 3.62 & 0.85 & $\mathrm{HE}$ \\
\hline 2. Promotes a sustainable business. & 3.54 & 0.85 & $\mathrm{HE}$ \\
\hline $\begin{array}{l}\text { 3. Attracts new investments from other } \\
\text { entrepreneurs. } \\
\text { 4. Improves business environment } \\
\text { through healthy competition. }\end{array}$ & 3.54 & 1.02 & $\mathrm{HE}$ \\
\hline 5. Promotes a reasonable retail price. & 3.92 & 0.74 & $\mathrm{HE}$ \\
\hline Average & 3.68 & 0.85 & $\mathrm{HE}$ \\
\hline
\end{tabular}


Currently, the idea of competitiveness has gained a significant presence, both internationally and locally (Cisneros, Torres, \& Flores, 2017). Furthermore, MBEs' principles of promoting the economic competitiveness of local industries regarding progress and exports have attracted controversy and debates. In regards to the discussion, they argued that the introduction of flexible production embraces substantial promise for a regeneration of the small-scale industrial sector (Maloka, 2013).

Poverty Alleviation. Table 8 shows that the extent of the economic contribution of MBEs to poverty alleviation as a whole is high ( $M=3.75 ; \mathrm{SD}=0.88)$. It implies that the standard of living improves as income pours into the family. Poverty is eradicated, and new life is slowly beginning. Businesses established help low-income family in improving their way of living. Poverty is one social problem that microenterprise society has that is addressed when ventures in the local community prosper. It gives residents a source of income or an opportunity to increase their financial capabilities. Accesses to reasonably priced goods and services, children are sent to school, and the ability to acquire necessities are some of the benefits when Micro Business Enterprises grow in the local community. Poverty can be eradicated when both the local government and people in business join hands in providing opportunities for employment to residents.

Based on the results of the survey, it is shown that "necessities like food, shelter, and water are met" and got a high score of 4.08 and were interpreted as high extent. The adversity in life, like a lack of money to spend on basic needs, is eliminated with business engagement. The business income supports the family's needs daily. "Provision of the minimum wage to the employees" got a low mean score of 3.23 and was interpreted to a moderate extent. The MBEs hire employees and provide them with minimum wage. To some employees, this may be not enough to sustain their daily needs, especially those with prominent families.

According to Edoho (2016), the author emphasized that entrepreneurship micro, small, and medium enterprise (MSME) strategy can reduce the high unemployment rate and alleviate crippling poverty. Strengthening entrepreneurship has been recognized as a mechanism of producing employment and is a powerful weapon of fighting poverty in the country.

The economic status of the family improves when opportunities for employment and lower prices of goods and services are present in the community. For any nation to realize growth, industrialization, and having gainful and meaningful employment are relevant indices used to measure economic progress, typically represented by income per capita, equitable distribution of income, welfare, and quality of life enjoyed by the citizen (Opafunso et al., 2014).

Financing micro-entrepreneurs for job creation and income-generating activities shows success in many developing countries. Poverty alleviation is necessary to deal with any effective program related to sustainable development. It was given top priorities for international development because one-fifth of the world population is living in extreme poverty (Khanam, Mohiuddin, \& Hoque (2018). 
Table 8. Extent of Economic Contribution of MBE in terms of Poverty Alleviation

\begin{tabular}{|c|c|c|c|}
\hline Poverty Alleviation & Mean & SD & Int \\
\hline 1. Provides minimum wage to the employees. & 3.23 & 0.9 & ME \\
\hline 2. Employees can send their children to school. & 3.85 & 0.87 & $\mathrm{HE}$ \\
\hline $\begin{array}{l}\text { 3. There is sufficient basic necessity like food, } \\
\text { shelter, water, and clothing. }\end{array}$ & 4.08 & 0.84 & HE \\
\hline 4. Provides sustainable livelihood for everyone. & 3.77 & 0.81 & HE \\
\hline 5. Gives access to cheaper goods and services. & 3.85 & 0.78 & HE \\
\hline Average & 3.75 & 0.88 & $\mathrm{HE}$ \\
\hline
\end{tabular}

Extent of Economic Contribution. As shown in Table 9, the extent of the economic contribution of Micro Business Enterprises to local development as a whole is high ( $M=3.65 ; \mathrm{SD}=0.85)$.

This indicates that Micro Business Enterprises in the community "alleviates poverty," which got a high mean score of 3.75 and was interpreted as high extent while "income generation" got a low mean score of 3.52 and also interpreted as high extent.

According to Debela (2014), the contribution of MBEs toward employment, poverty reduction, entrepreneurship, and innovation is growing in importance. Micro enterprises are noted for sizeable proportions of urban jobs and also considered as the "vital component of urban economies." The economic contributions of micro business to the growth and development of the economy is of prime importance in uplifting the financial status of the residents and the delivery of essential services of the local government.

This validates the theory of the study that economic development and growth occurs when there is support from the local government and open access to financial services over and above the resources invested by the micro business owners.

Table 9. Extent of Economic Contribution of Micro Business Enterprise

\begin{tabular}{lllc}
\hline \multicolumn{1}{c}{ To } & Mean & SD & Interpretation \\
\hline Income Generation & 3.52 & 0.81 & $\mathrm{HE}$ \\
Local Competitiveness & 3.68 & 0.85 & $\mathrm{HE}$ \\
Poverty Alleviation & 3.75 & 0.88 & $\mathrm{HE}$ \\
As a Whole & $\mathbf{3 . 6 5}$ & $\mathbf{0 . 8 5}$ & $\mathrm{HE}$ \\
\hline Note: HE=High Extent & & &
\end{tabular}

Prevailing Challenges Faced by MBEs. Table 10 presents a summary of the prevailing challenges MBEs faced. Entrepreneurs struggle to operate and make their businesses profitable successfully. Based on the survey, the top most prevailing challenges faced by MBEs was the existence of new competitors, which got the highest percentage of $84.60(n=33)$. It is a natural phenomenon that competition is a prevailing economic challenge, especially when someone ventures in business. New 
competitors are threats to the profitability of the existing business. The emergence of new competitors lowers the income of existing or old businesses. It affects the incomegenerating activities; thus, it is a challenge for entrepreneurs to design strategies to counter the effects. The specific nature of competition in the market for products or services made is of particular importance for the participants to obtain a competitive advantage over rivals. Therefore, competitiveness in an open market is a central issue, and the corresponding formulation of competitive strategy is crucial for the survival and development of institutions and enterprises (Zelga, 2017).

Competition leads to lower prices. As a result, business profit is low; this is also considered as a challenge for MBE owners to grow profitably. Based on the study conducted by (Carter, 2019), competition causes low profit to the business. It is stated in his study that net profit margins have declined for both food and non-food retailers over recent years.

Challenges like the cost of technology for the installation of new business processes or systems, and the high rate of employees turn over are also considered detrimental to the operations of the business. Innovation and technological infrastructure are quite expensive, which micro-business owners found to be costly and affect the cash flow of the business.

Employee turnover is the rate at which employees depart a company and have to be replaced by new or existing staff. The issue of employee turnover has raised quite a several concerns in the construction industries as a result of its effect on productivity. It is a known fact that employees are important stakeholders in the firm, but unfortunately, after limited resources have been used in recruiting, training and developing the employees, they leave for other organizations (Ade Abdulquadri, 2015).

Table 10. Prevailing Challenges Faced by MBE

\begin{tabular}{lll}
\hline Challenges & $\mathrm{f}$ & $\%$ \\
\hline Existence of new competitors & 33 & 84.6 \\
Low profits & 24 & 61.5 \\
$\begin{array}{l}\text { Cost of technology } \\
\text { Employee turnover (Fast Employee }\end{array}$ & 21 & 53.8 \\
Resignation) & 21 & 53.8 \\
Access to financial services & 18 & 46.2 \\
Limited access to markets & 12 & 30.8 \\
Lack of Barangay Micro Business & 9 & 23.1 \\
Enterprise campaign & 9 & 23.1 \\
Lack of management skills & 9 & 23.1 \\
$\begin{array}{l}\text { Low demand for product and services } \\
\text { Others (Specify): High Demand, Low }\end{array}$ & & \\
Supply & 1 & 2.6 \\
\hline
\end{tabular}

The results of the study show that MBE's significantly contribute to the local development of the economy as it provides income to the residence of the community, 
alleviating poverty. These results have reflected the impact of business operation where it provides infrastructural development, job creation, higher tax collection, and improve business process. Moreover, business enterprises encounter challenges like competition, high rate of employment, low profit, and high cost of technology, but it can be solved through effective and efficient management.

\subsection{Conclusion}

At the outset, micro-business owners play a vital role in the success of the selected business venture. In all aspects of the business, business owners and managers have direct control over the operation and decision-making process of the business. The economic impact, contributions, and challenges of Micro Business Enterprises on the local economy give both macro and micro perspectives of their operational efficacy. The economic impact which considers infrastructural development, job creation, tax collection, and technology indicates the after-effects of the business operation of micro-enterprises. The findings imply that Micro Business Enterprises are deeply rooted in the entrepreneur's commitment to do business that promotes progress to the local economy. Results signify that the presence of micro-businesses in the local community can help improve the economy and the peoples' standard of living as this will provide revenue to the local government and employment to residents. It is brought about by many participants that are interested in being local entrepreneurs or in doing business on a micro-scale level.

Further, Micro Business Enterprises contribute to local economic development other than by providing employment opportunities to the residents and supporting local government unit's delivery of essential services. MBEs boost local entrepreneurship.

Prevailing challenges faced by Micro Business Enterprises affect their operational efficiencies. These challenges reduce profits and heighten competition. There are specific issues that the local government unit can address, like providing access to financial services and assistance in upgrading to new emerging technologies.

Micro Business Enterprise owners, for effective management, may consider using the data in designing and formulating or drafting policies and procedures on purchasing, distribution, hiring, and financing. MBE owners should organize their businesses based on their capabilities and resources invested.

Challenges faced by MBEs and these emerging issues are to be answered for sustainable business operations. To prospective investors, findings of the study give potential investors insights as to the challenges faced by MBEs as well as the weak areas of the business operation that need focus when they eventually venture into business. These challenges identified need to be addressed to achieve business objectives and desired profits.

The local government agency may explore the possibility of assisting microbusinesses in gathering information for periodic evaluation and monitoring of the financial status of micro-businesses for reporting purposes. It is hoped that future researchers utilize this study as a basis for further research, especially studies that will focus on the impact assessment of Micro Business Enterprises, financial literacy, and readiness for skill transfer and technology prospects. 


\section{REFERENCES}

Abellanosa, R. A. (2014). HB0 4007 Republic Act on Micro, Small, Medium Enterprises. Quezon City, Metro Manila.

Adebisi, J. P. \& Gbegi, D. O. (2013). Effect of Multiple Taxation on the Performance of Small and Medium Scale. Mediterranean Journal of Social Sciences, 4 (6), 327.Doi:10.5901/ mjss.2013.v4n6 p.323.

Ade Abdulquadri, B. (2015). Impact of Employee Turnover in Small and Medium Construction Firms: A Literature Review (Vol. 4 Issues 02). International Journal of Engineering Research \& Technology (IJERT). ISSN 2278-0181

Almerino, J. A. (2016). Tax Exemption and More: Take Advantage of the Incentives Provided by the Barangay Micro Business Enterprise Act. Retrieved from: http://foundersguide.com/ incentives-tax-exemption-brgy-micro-business- enterprises-act/.

Ajuwon, Ikhide, and Akotey (2015). Micro, Small, and Medium Enterprises (MSMEs) and Employment. The Journal of Developing Areas, 51 (3).

Aruna, N. (2015). Problems Faced By Micro, Small, and Medium Enterprises - A Special Reference to Small Entrepreneurs in Visakhapatnam. 17 (4), pp. 43-49. e-ISSN: 2278-487X, p-ISSN: 2319-7668.

Baptiste-Cornelis, T. \& Long, W. (2015). The Impact of Small Business Enterprises on the Economy of Trinidad and Tobago. International Journal of Arts and Commerce.

Berry, Albert, and Mazumdar, D. (1991), "Small-Scale Industry in the Asian-Pacific Region," AsianPacific Economic Literature, 5(2).

Bobowski, S. (2017). Japanese Micro, Small and Medium Enterprises (MSMES) In ASEAN JaposkieMikro, Male. (486).

Carter, M. (2019, Competition and Profit Margins in the Retail Trade Sector. Reserve Bank of Australia, Bulletin.

Cisneros, M., Torres, A., Flores, M. (2017). Business competitiveness in the small and medium-sizedenterprises of the manufacturing sector in Baja California Estudios Fronterizos,18(35), January-April, 2017, pp. 107-130, 18 (35), pp.107., e-ISSN 23959134130.https://doi.org/10.21670/ref.2017.35.a06.

Chowdhury, P. (2016). Contribution of Micro and Small Enterprises of Bangladesh: An Empirical Study Contribution of Micro and Small Enterprises of Bangladesh. (February).

De Renzy, E. (2014). Investing locally: The Economic Impact of Microenterprise on the Community.

Debela, E. B. (2014). The Role of Micro and Small Enterprises (MSE) in Local Economic Development (LED), with a focus on the wood-work MSE value chain. p. 9-10. 
Edoho, F. M. (2016). Entrepreneurship paradigm in the new millennium. Journal of Entrepreneurship in Emerging Economies; 8 (2), 279-294. DOI 10.1108/JEEE-08-2015-0043.

Hassan, T, \& Ahmad, B. (2016). The Role of Micro Enterprises in Employment and Income Generation: A Case Study of Timergara City Dir (L) Pakistan. International Journal of

Economics Management Science 5: 318.http://dx.doi.org/10.4172/2162-6359.1000318.

Ismael N. W., and J. M. Mahyideen. (2015). The Impact of Infrastructure on Trade and Economic Growth in Selected Economies in Asia. Asian Development Bank Institute No. 553.

Jha, R. (2017). Role of Microenterprises in recovering U.S. Economy- Post-2008 Financial Crisis. $19(3), 9-28$.

Khanam, D., Mohiuddin, M. \& Hoque, A. (2018). Financing Micro-Entrepreneurs for Poverty Alleviation: A Performance Analysis of Microfinance Services offered by BRAC, ASA, and Proshika from Bangladesh. Journal of Global Entrepreneurship Research, Vol.8, Article Number 27. https://doi.org/10.1186/s40497-018-0114-6.

Magar, S. (2017). "Infrastructure - Contribution and Challenge for Development of Micro, Small, and Medium Enterprises."

Maloka, C. M. (2013). The Contribution of Small, Medium, and Micro Enterprises towards Local Economic Development in Mankweng Township.

Navarathne, K. (2017). Challenges Faced by Small and Micro Enterprises in Sri Lanka. Urban and Regional Planning. Vol. 2, No. 6, 2017, pp. 34-37.

Nishanth, P. (2014). Barriers Faced by Micro Small and Medium Enterprises in Raising Finance. 3 (5), 39-40.

Opafunso, Z. \&Adepoju, O. (2014). The Impact of Small and Medium Scale Enterprises on EconomicDevelopment of Ekiti state, Nigeria. Journal of Economics and Sustainable Development, 5 (16), 115-123.

Popescu, Corbos, and Bunea (2018). Influences on Urban Competitiveness Development from the Perspectives of Business and Local Authorities. Revista de Management Comparative International; 19 (4), 359-371.

Ramírez-Urquidy, M., et al. (2018). The Impact of Economic and Financial Management Practices on the Performance of Mexican Micro-Enterprises: A Multivariate Analysis. 20 (3), 319-357.

Simbre, R. \& Sta. Maria, M.L. (2017). Effectiveness of the Implementation of Barangay (Community) Micro Business Enterprise Law. The International Journal of

Zelga, K. (2017). The Importance of Competition and Enterprise Competitiveness. WSN 72 (2017) 301-306 EISSN 2392-2192, 72, 301-306 
Vitez, O. (2018). The Impact of Technological Change on Business Activity Small Business-Chron.com

World Economic Forum. 2014. Global Competitiveness Index. Retrieved from http://www. weforum.org/reports.

Yahaya, H. D, Geidam, M. M., Usman, M. U. (2016). The Role of Micro Small and Medium Enterprises in the Economic Development of Nigeria. International Journal of Small Business and Entrepreneurship Research Vol.4, No.3, pp.33-47, European Centre for Research Training and Development UK, 4 (3), 33-47. ISSN: 2052-6385 